\title{
Dilatancy as a measure of fracturing development in the process of rock damage
}

https://doi.org/10.1515/geo-2018-0038

Received May 08, 2018; accepted Jul 31, 2018

\begin{abstract}
Dilatancy understood as inelastic volume changes of rock under conditions of differential stress not only foreshadows brittle rock failure [1-3], preceding such phenomena as earthquakes or mining-induced rockbursts, but also defines the kinematics of rock deformation $[4,5]$. This article shows that there is a quantitative relationship between the dilatancy occurring at different levels of rock load and the development of fracturing that accompanies the process of rock degradation. Based on the mechanical laboratory test results of Wustenzelleer fine-grained sandstone, the article presents analyses of plastic volume changes in rock samples and a certain measure of fracture development accompanying the process of their degradation. Thanks to the characteristics obtained through mechanical tests with unloading, the inelastic volumetric strain of the samples was established, and the scalar damage variable (CDM - continuum damage mechanics approach) was determined at various load levels. These results demonstrated the relationship between dilatancy and rock stiffness changes describing the development of fracturing. Three load intervals were determined, in which the nature of the analysed phenomena, i.e. dilatancy and damage describing the development of cracks, undergoes significant changes. The highest intensity of both phenomena was obtained in the post-critical load range, between the ultimate strength limit and the residual strength of the samples, in which rock samples undergo the process of degradation the most. Obtained dependencies allow the correlation to be taken into account in damage mechanics models describing the variable stiffness of rocks in the loading process.
\end{abstract}

Keywords: rock laboratory investigations, volume changes, rock damage

\footnotetext{
^Corresponding Author: Jerzy Cieślik: Department of Geomechanics, Civil Engineering and Geotechnics, AGH University of Science and Technology, 30-059, Krakow, Poland;

Email: jerzy.cieslik@agh.edu.pl
}

\section{Introduction}

Dilatancy as inelastic volume changes is observed in rock at quite low load levels both in laboratory tests $[1-3,6,7]$ and in situ observations $[8,9]$. It has considerable practical significance due to the possibility of it being used to predict the failure of the rock mass. Owing to this, it can be treated as a precursor of such phenomena as shocks, earthquakes or mining rockbursts [1] and, as reported by Andersson et al. [9], for investigating the onset of spalling (cracking) in fractured rock mass.

Its effect is initially relative, and from a certain level of load, an absolute increase in rock volume can also be observed, despite the impact of compressive loads. In hard, brittle rocks it occurs practically under any load condition; however, in porous rocks it depends on the hydrostatic pressure component $[10,11]$. Dilatancy has its source in the microstructure of the rock and is the result of slips on the initially existing microfractures, grain boundaries, as well as on newly formed fractures [12, 14]. For example, the study [12] authors divide the mechanisms of microcrack nucleation in marble into four types (Figure 1). The type I mechanism is where a packet of twin lamellae, which intersected a grain boundary, caused the tensile stress concentration which nucleated the crack. The type II mechanism is when the glide lamella is blocked by an obstacle and the crack forms along the lamella. In the third mechanism (observed in the Tennessee marble) it is possible to create microcracks that do not require the presence of a grain boundary. The IV mechanism consists of a plastically yielding grain surrounded by non-yielding grains [12].

In the case of newly formed cracks, dilatancy is then a kind of derivative and the effect of the microcracking process, and is closely related to it. At the macroscopic level, these phenomena can be observed in the form of permanent deformations, while when analysing the mechanical characteristics of the samples - after unloading. It is assumed that dilatancy is initiated by the relative dilatancy threshold $O D$ (see Figure 2) [2, 7], which can be determined by several methods $[15,16]$. 


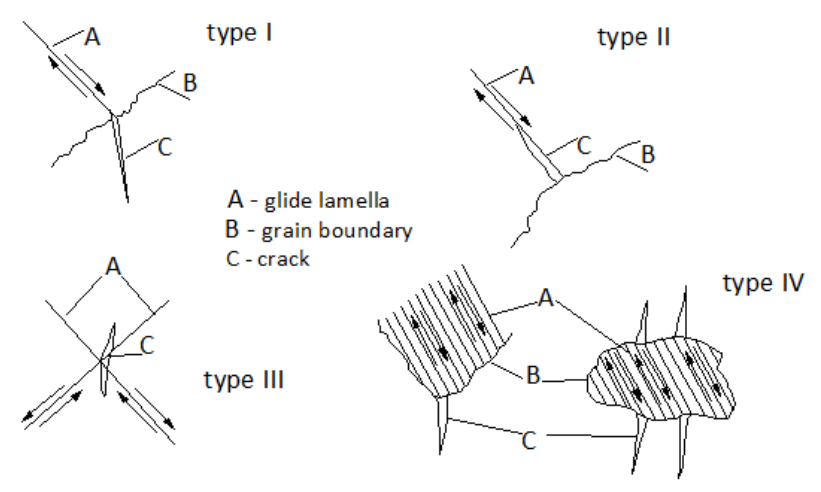

Figure 1: Microcrack nucleation and propagation mechanisms based on microscopical observations [12]

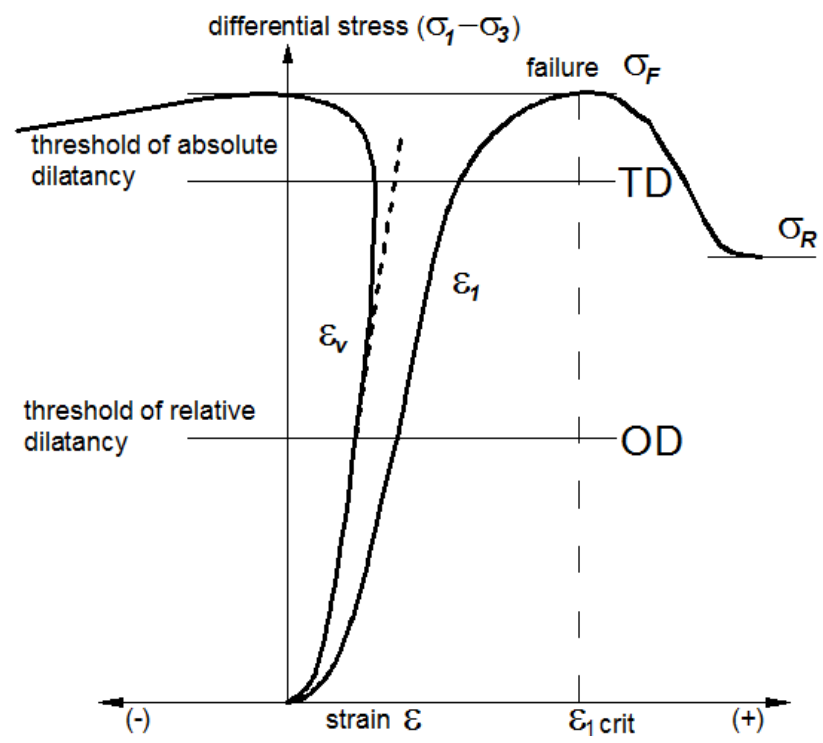

Figure 2: Idealized stress- strain characteristics with threshold of relative dilatancy $O D$, threshold of absolute dilatancy $T D$ and failure stress $\sigma_{F}$. Compaction has a positive sign. (after [7])

Brace et al. [2] and Kwaśniewski [6, 7] show that in the stress-strain characteristics (Figure 2) one can find the following thresholds and stages:

- crack closure, observed in the axial $\sigma_{1}$ or differential $\left(\sigma_{1}-\sigma_{3}\right)$ stress-axial strain $\epsilon_{1}$ relation at the beginning of the loading process up to its linearity,

- crack initiation or onset of dilatancy $O D$, observed in the volumetric strain $\epsilon_{V}$ characteristic (threshold of relative dilatancy),

- unstable crack growth $T D$ understood as the threshold of absolute dilatancy, when the volumetric strain $\epsilon_{V}$ has a maximum value,

- ultimate strength $\sigma_{F}$.

- residual strength $\sigma_{R}$.
For sedimentary rocks, the threshold of relative dilatancy is usually 0.2-0.5 $\sigma_{F}$. After crossing the threshold of relative dilatancy, despite the relative increase in volume, rock is subject to compaction. Only exceeding the threshold of absolute dilatancy $T D$ causes an absolute increase in the volume of rock. For brittle and strong rocks this threshold often occurs close to the limit of $\sigma_{F}$; however, in weaker or porous rocks, it may be close to $0.5 \sigma_{F}$. The nature of dilatancy is variable and depends on the mechanism of failure, in the form of axial splitting, single shear or shear bands. Regardless of the mechanism of failure, its course can be divided into three intervals, corresponding to the pre-critical part (from TD to $\sigma_{F}$ ), post-critical range (from $\sigma_{F}$ to $\sigma_{R}$ ) and residual part (beyond $\sigma_{R}$ ) of the sample load characteristics [4-6].

In turn, the development of cracks accompanying the degradation of rock has an extremely complicated, random character, and is therefore difficult to observe. Microcracks can be tracked directly on the basis of microscopic analysis $[12,14,17,18]$ or computed tomography [20]. The tests confirmed that the development of cracks occurs mainly through the initiation and development of initial micro fractures and their merging into a single macrocrack [18, 21] or into shear bands [14, 22]. Practical observations and quantitative analyses of microcracks in rocks, however, are carried out mainly indirectly, through effects associated with fractures, i.e. changes in the stiffness of samples, changes in the velocity of elastic waves, or acoustic emission during the loading process. These methods allow to determine certain measures, both scalar and tensor, thanks to which the description of the usually anisotropic character of microcracks is possible [14, 21]. In this article, the method of axial stiffness changes of rock samples and scalar damage variable (CDM) was used to describe the development of cracks in sandstone samples at various load levels. This is possible thanks to the utilisation of the sample tests characteristics with unloading.

The main goal of the paper is an attempt to link the changes in the axial stiffness of the samples with the corresponding inelastic volume strains (dilatancy) registered in the sandstone damage process. These dependencies, relatively simple to be determined in laboratory tests, can be applied to define elastic-plastic models, with damage used to describe the inelastic behaviour of rocks [23, 24] and other brittle materials, e.g. concrete $[25,26]$. In the continuum damage mechanics models, there is a need to define material functions that describe the evolution of damage variables. The experimentally determined relationship presented in this article can be used as a function of the evolution of scalar damage variable. 


\section{Methods of rock sample testing}

\subsection{Mechanical tests of sandstone samples under uniaxial and triaxial compression}

The investigations were carried out on MTS servocontrolled Rock and Concrete Mechanics Testing System with MTS triaxial cell, model 656.11. The measurement of the axial force was carried out by a force transducer installed inside the pressure cell, while the displacements were measured by extensometers. Radial displacements were determined through the measurement of changes of the sample circumference with a chain placed around it, axial ones outside the cell, and measuring the piston displacement. Mechanical tests were carried out at a constant rate of axial strain of samples, which amounted to $1 \cdot 10^{-4}$ $\left[\mathrm{s}^{-1}\right]$. The test procedure for triaxial compression tests consisted of several stages (Figure 3).

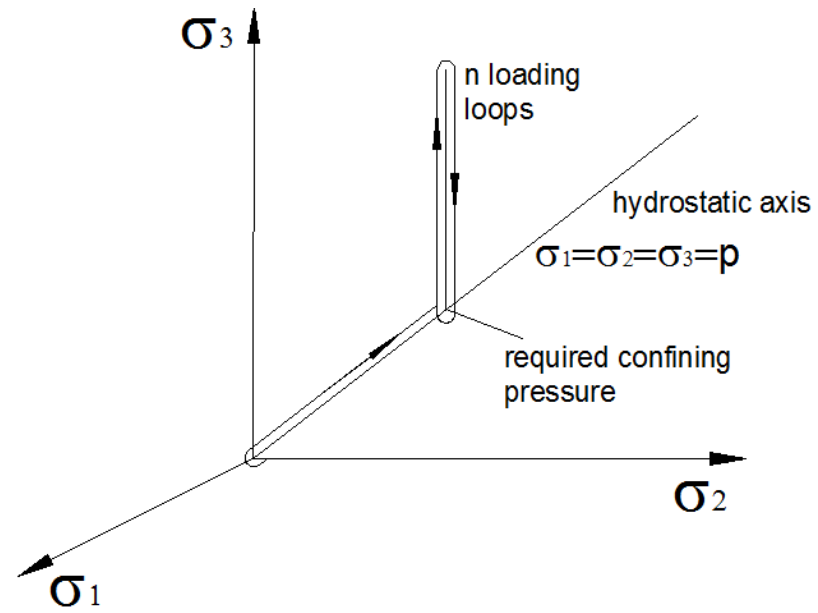

Figure 3: The test procedure for triaxial compression

After installing the sample in a triaxial chamber and filling it with mineral oil, confining pressure was applied to the desired value $(5,10,20,40,70 \mathrm{MPa})$. The axial force of the chamber piston was increased to a specific level of axial compression and then reduced to almost zero (usually $6 \div 10$ cycles of axial loads). The uniaxial (UCS) tests were carried out in a similar manner, without the first stage of applying confining pressure. All rock samples tested were cylindrical and cut out from the rock block, and their dimensions were: height $h=70 \mathrm{~mm}$, diameter $d=35 \mathrm{~mm}$. There were 23 rock samples investigated, five with uniaxial compression and eighteen with conventional triaxial compression.
Figure 4 presents sample stress-strain characteristic $\sigma_{1}-\epsilon_{1}$ of the test with unloading obtained for sandstone in uniaxial compression. The volumetric strain $\epsilon_{v}$ was obtained with formula (1).

$$
\varepsilon_{V}=\varepsilon_{1}+2 \varepsilon_{2}
$$

$\epsilon_{1}, \epsilon_{2}$ - axial and lateral strain,

$\sigma_{1}$ - axial stress

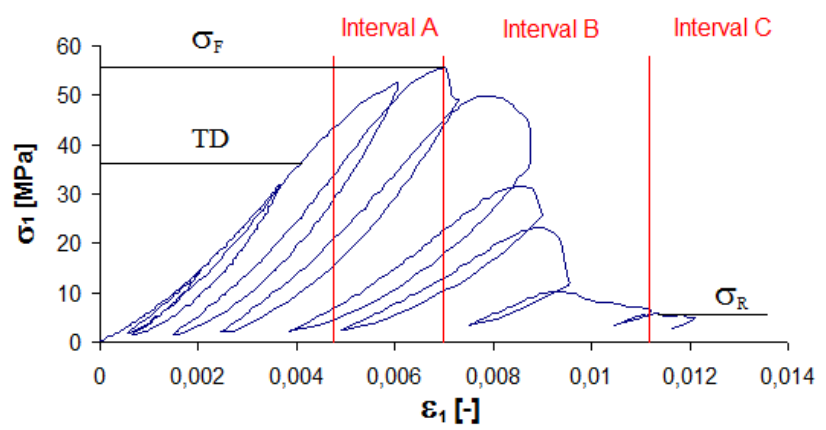

Figure 4: Example sample stress-strain characteristic obtained for sandstone for uniaxial compression with unloading

Plastic volumetric strain $\epsilon_{v o l}^{p l}$ was determined on the basis of strain read from the test characteristic with unloading (Figure 5).

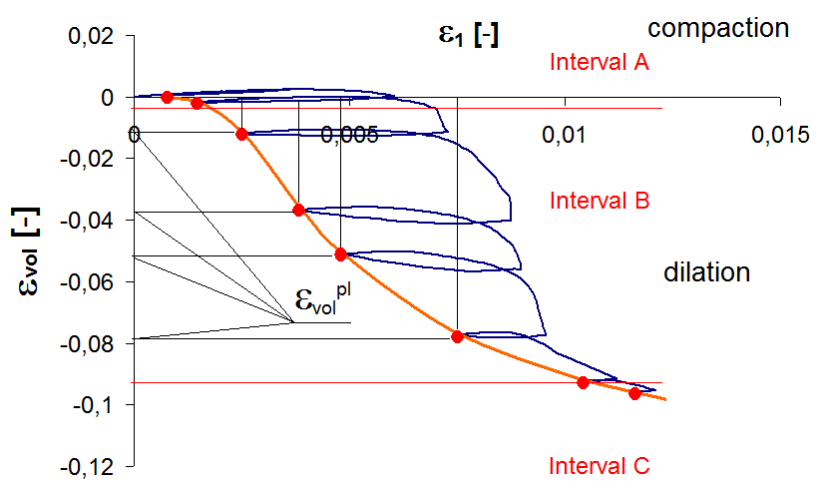

Figure 5: Volumetric changes $\epsilon_{v o l}$ for sandstone sample in uniaxial compression test

Analysing the obtained sample results (Figure 4 and Figure 5), inelastic volumetric strains $\epsilon_{v o l}^{p l}$ (dilatancy) where considered in three intervals:

- Interval A - from the threshold of absolute dilatancy $T D$ to the ultimate strength $\sigma_{F}$

- Interval B - from $\sigma_{F}$ to the residual strength $\sigma_{R}$

- Interval C - beyond the residual strength $\sigma_{R}$ 
The scalar damage variable $D_{E}[23,24,27]$, which describes the changes in the axial stiffness of the rock samples (2) in pre and post-critical load range, was used to describe the development of cracks in the sandstone (Figure 6). This assumption entails that the development of cracks is treated here as an isotropic phenomenon.

$$
D_{E}=1-\frac{E_{S}}{E_{s \max }}
$$

$D_{E}$ - scalar damage variable, takes the value $0<D_{E}<1$, $E_{S}$ - actual value of the local Young's modulus determined with unloading,

$E_{S \max }$ - maximum value of the local Young's modulus.

For large values of $E_{s}$ close to $E_{s}$ max we get small values of $D_{E}$ close to zero. For small values of $E_{s}$, usually in the post failure loading range, $D_{E}$ become close to one.

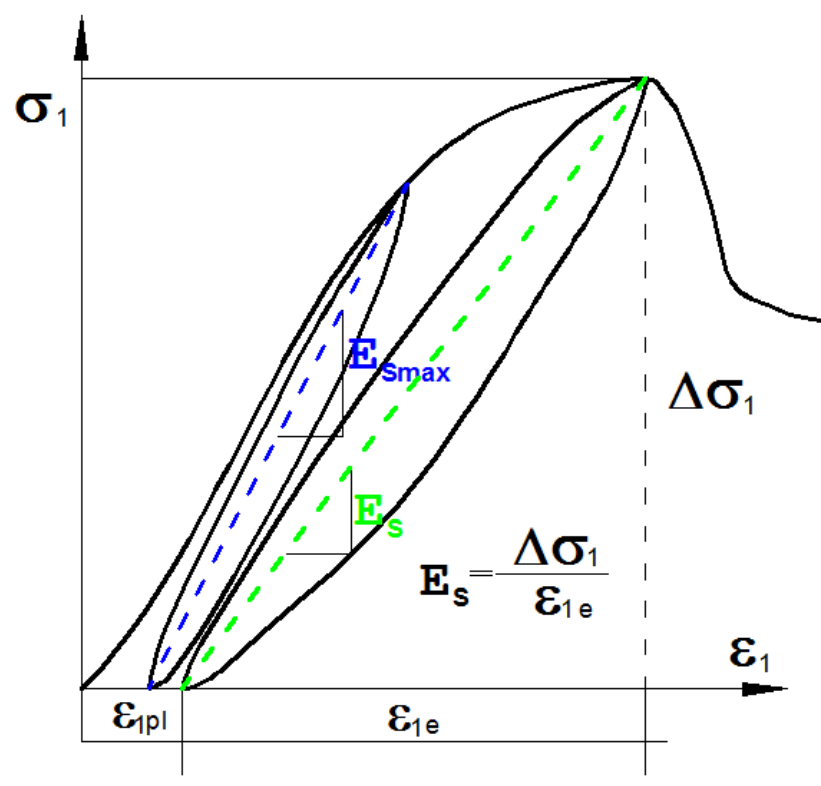

Figure 6: Local Young's modulus $E_{S}$ definition (2)

As can be seen, both the scalar damage variable $D_{E}$ (Figure 6) and the corresponding dilatancy value $\epsilon_{v o l}^{p l}$ (Figure 5) for a given sample were determined at the same load levels.

In the continuum damage mechanics homogenisation of micro cracks, fractures and pores occur thanks to the definition of inner state variables called damage variables [28, 29]. Damage variables can be defined as scalar, vector or tensor quantities of various orders, depending on the evolution of the damage. On the basis of the equivalence principle (Figure 7), a concept of the so-called effective values of stress $\tilde{\sigma}$ (3) and strain $\tilde{\varepsilon}$ (4) is being introduced instead of stress $\sigma$ and strain $\epsilon$ concepts, in the con- tinuum damage mechanics.

$$
\begin{gathered}
\tilde{\sigma}=\frac{\sigma}{\left(1-D_{E}\right)} \\
\tilde{\varepsilon}_{e}=\varepsilon_{e}
\end{gathered}
$$

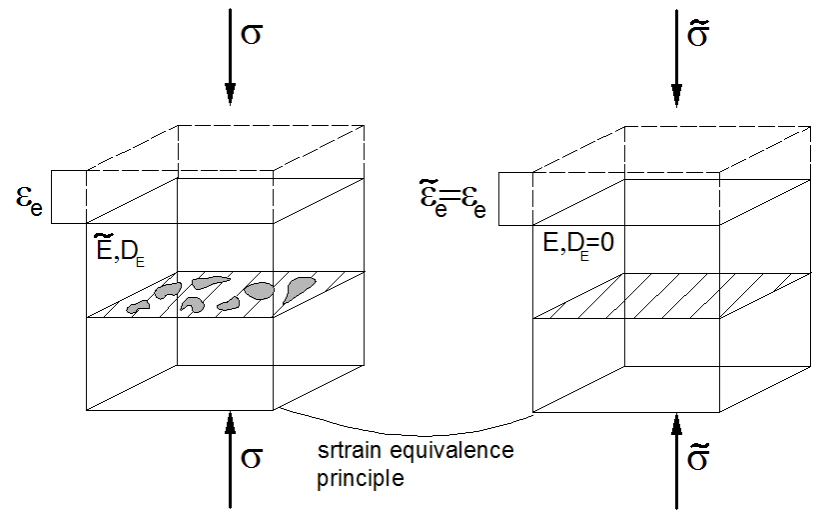

Figure 7: Strain equivalence principle in continuum damage mechanics $[27,29]$

\section{Discussion of the laboratory tests results}

\subsection{Volume changes in sandstone samples}

The dilatancy at a given load level was established on the basis of inelastic volume strains read from the test characteristics of the samples with unloading for all the performed tests. As can be observed (Figure 5), volumetric changes in the first interval $A$ are relatively small and largely correspond to the compaction. In the second interval $B$, the biggest changes in dilatancy are recorded, and the curve of inelastic volume changes has the greatest inclination, while in the third interval $C$, inelastic volumetric changes slowly disappear. It should be emphasised that from a physical point of view, volumetric changes in interval $C$ should not take place, are dependent on measuring method and should be negligible.

The results of dilatancy $\epsilon_{v o l}^{p l}$ obtained for uniaxial compression tests are presented in Figure 8 and for all tests (unconfined and confined) in Figure 9.

The highest increase of dilatancy value can be observed in the interval $B$ between the ultimate strength $\sigma_{F}$ and the residual strength $\sigma_{R}$ of the samples for $\epsilon_{1} / \epsilon_{1 \text { crit }}>$ 


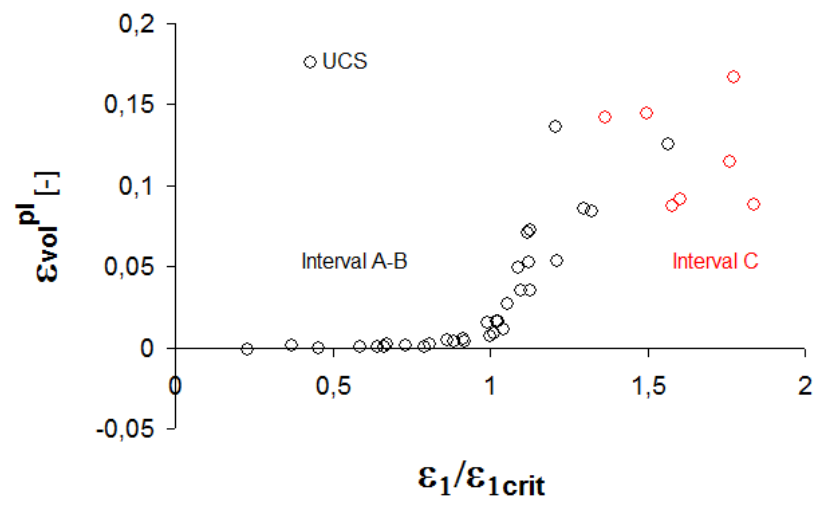

Figure 8: Dilatancy results obtained for uniaxial compression tests

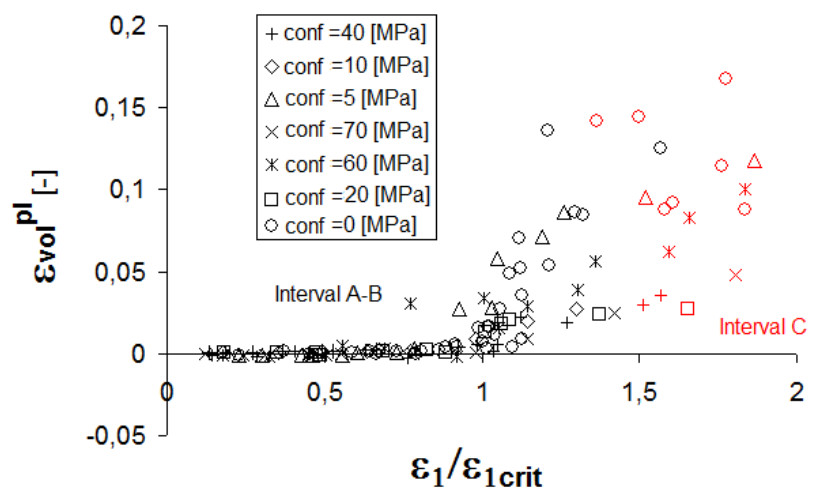

Figure 9: Dilatancy results obtained for uniaxial (UCS) and confined compression tests

1. After exceeding the threshold of residual strength $\sigma_{R}$, (points in red colour) dilatancy slowly stabilizes on a certain level depending on the confining value.

Qualitatively similar results were obtained in $[4,5,30$, 31] where, among others the variability of the dilatancy angle was determined as a parameter of the elastic-plastic mechanical model.

\subsection{Development of cracks and the changing stiffness of sandstone samples}

In Figure 10 it can be noticed that the stiffness of the samples in the pre-critical load range (up to ultimate strength $\sigma_{F}$ ) first increases and then decreases - when it is close to the critical strain value $\epsilon_{1} / \epsilon_{1 \text { crit }}=1$. It can be assumed that this is the result of two overlapping phenomena. The first is related to the progressive development of microcracks, which results in the softening of the sample. The second - to the compaction of pores and primary cracks, which causes the sample to strengthen. Both opposing phenomena overlap in the interval $A$. Once the limit of ultimate strength $\sigma_{F}$ is exceeded $\epsilon_{1} / \epsilon_{1 c r i t}>1$, the phenomenon of microcracks development prevails and leads to macrocracking and sample degradation.

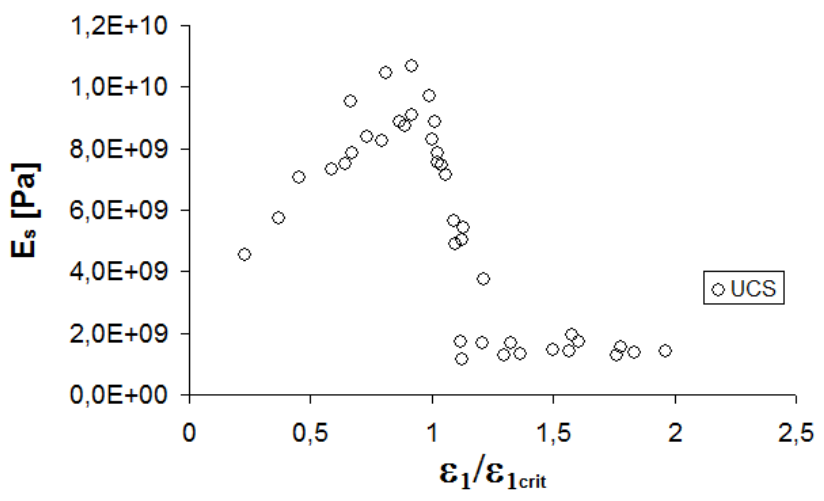

Figure 10: Changes in axial stiffness $E_{S}$ of sandstone samples for uniaxial compression tests

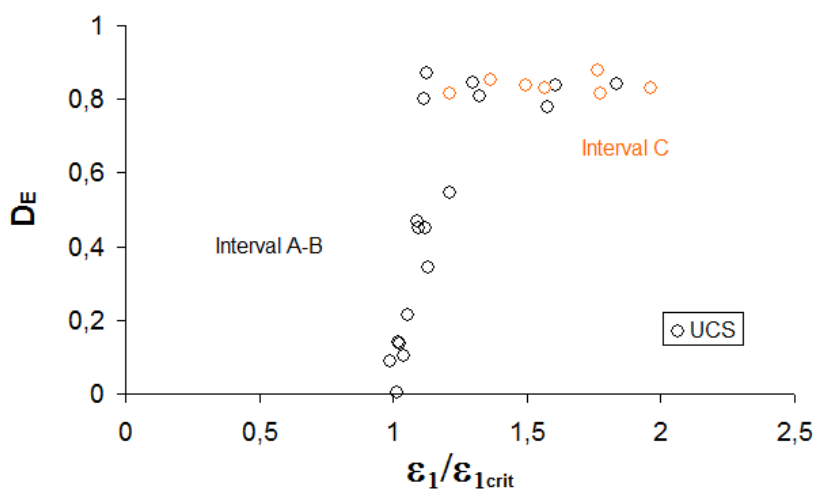

Figure 11: Changes in scalar damage variable $D_{E}$ of sandstone samples for uniaxial compression tests

The values of scalar damage $D_{E}$ determined on the basis of axial stiffness changes (4) in five uniaxial compression tests are shown in Figure 11. The damage described by $D_{E}$ measure is evident at the level of the load corresponding to the compressive strength. The highest increases in the variable damage can be observed in the interval $B$ between the compressive strength limit and the residual strength of the samples. After exceeding the threshold of residual strength $\sigma_{R}$ (points in red colour), the value of the damage variable $D_{E}$ remains constant.

The development process of cracks and damage measured with scalar variable $D_{E}$, in the case of triaxial compression tests, has a similar course (Figure 12).

In this case, however, the maximum value of damage variable $D_{E}$ depends on the pressure surrounding the test. 


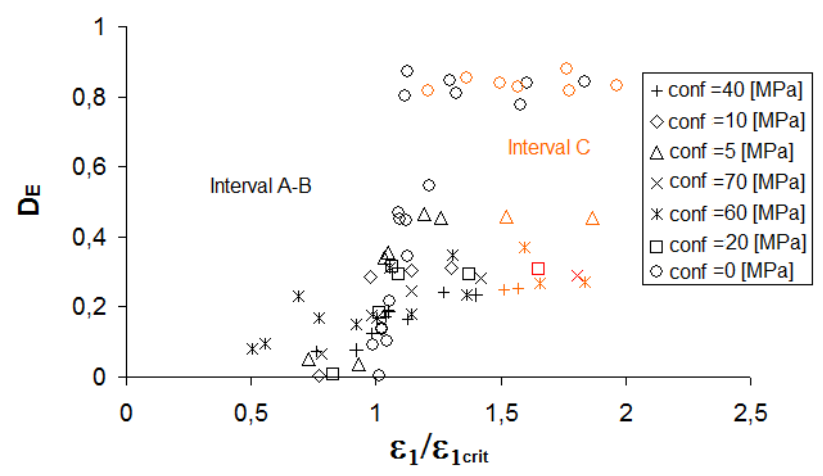

Figure 12: Scalar variable $D_{E}$ values in the case of unconfined and confined (triaxial) compression tests

This is the effect of rock strengthening at higher pressures surrounding the tests and the transition from a brittle to quasi-ductile state.

\subsection{The relationship between the development of cracks and dilatancy}

If we compare qualitatively the changes in dilatancy and the development of cracks in the three previously proposed intervals, we can see a clear similarity in the intensity of both studied phenomena. The most intense changes of both dilatancy and damage variable $D_{E}$ occur in the interval $B$, where the rock samples are weakened and undergo a process of degradation. The final dependence determined for interval $B$ of the analysis, between the damage variable $D_{E}$ and the dilatancy $\epsilon_{v o l}^{p l}$, is presented in Figure 13.

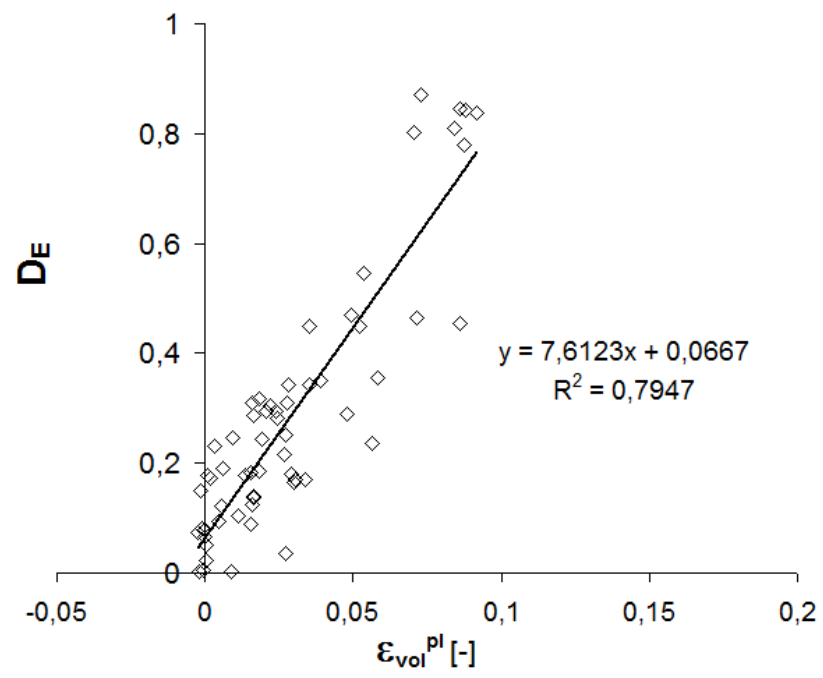

Figure 13: The relationship between damage variable $D_{E}$ and dilatancy $\epsilon_{v o l}^{p l}$ for all performed tests
Its character for small dilatancy values $\epsilon_{v o l}^{p l}<0.025$ is non-linear. However, in the entire deformation range, it can be treated as a linear one, and it was for this form of the function that the parameters of the equation approximating the test results were determined (Figure 13).

\section{Conclusions}

The article presents the results of tests describing the development of cracks and inelastic volume changes (dilatancy) of fine-grained sandstone in the conditions of uniaxial and triaxial compression. Three load intervals were determined, in which the nature of the analysed phenomena, i.e. dilatancy and damage describing the development of cracks, undergoes significant changes. The highest intensity of both phenomena was obtained in the postcritical load interval, between the ultimate strength limit and the residual strength of the samples, in which rock samples are weakened and undergo a process of degradation. At the level of residual strength, damage changes and inelastic volume changes can be omitted.

The above assumptions determined a linear relationship between dilatancy and damage variable describing the development of cracks. The obtained results indicate that dilatancy not only foreshadows the destruction of the rock but can also be a measure of its degradation. The obtained dependencies can be used to define the function of the evolution of the damage scalar variable describing the process of rock degradation.

Acknowledgement: This study is sponsored through the statutory research funds of the AGH University of Science and Technology, Faculty of Mining and Geoengineering within the framework of the research program $\mathrm{N}^{\circ}$ 11.11.100.277

\section{References}

[1] Kwaśniewski M., Dilatancy as a precursor of rock damage. Part 1 Physical aspect of the dilatancy. Przegląd Górniczy, 1986, 42, 42-49, (in Polish).

[2] Brace W.F., Paulding B.W. (Jr.), Scholz C., Dilatancy in the fracture of crystalline rocks. J. Geophys. Res., 1966, 71, 3939-3953

[3] Bieniawski Z.T., Mechanism of brittle fracture of rock, part IIexperimental studies. Int. J. Rock Mech. Min. Sci. Geomech. Abstr., 1967, 4, 407-423

[4] Alejano, L.R. \& Alonso, E., Considerations of the dilatancy angle in rocks and rock masses. Int. J. Rock Mech. Min. Sci., 2005, 42, 481-507 
[5] Zhao, X.G., Cai M., A mobilized dilation angle model for rocks. Int. J. Rock Mech. Min. Sci., 2010, 47, 368-384

[6] Kwasniewski M., Rodríguez-Oitabén P., Study on the dilatancy angle of rocks in the pre-failure domain. Harmonising Rock Engineering and the Environment - Qian \& Zhou (eds) Taylor \& Francis Group, London, ISBN 978-0-415-80444-8, 2012, 681-686

[7] Kwaśniewski M., 2007. Mechanical behavior of rocks under true triaxial compression conditions - volumetric strain and dilatancy. Arch. Min. Sci. 52, No 3, 409-435

[8] Zhao X., Cai M., Cai M., Considerations of rock dilation on modeling failure and deformation of hard rocks-a case study of the mine-by test tunnel in Canada. Journal of Rock Mechanics and Geotechnical Engineering, 2010, 2 (4), 338-349

[9] Andersson C., Martin C.D., Stille H., The Aspo pillar stability experiment: part II-rock mass response to coupled excavationinduced and thermal-induced stresses. Int. J. Rock Mech. Min. Sci., 2009, 46, 865-878

[10] Bésuelle P., Evolution of Strain Localisation with Stress in a Sandstone: Brittle and Semi-Brittle Regimes. Phys. Chem. Earth (A)., 2001, 26, No. 1-2, 101-106

[11] Schultz R.A., Siddharthan R., A general framework for the occurrence and faulting of deformation bands in porous granular rocks. Tectonophysics, 2005, 411, 1-18

[12] Olsson W.A., Peng S., Microcrack nucleation in marble. Int. J. Rock Mech. Min. Sci., Vol. 13, 1976, 35-59.

[13] Paterson M.S., Wong T.-f., Experimental Rock Deformation - The Brittle Field (2nd ed). Springer Verlag, Berlin Heidelberg, 2005

[14] Martin C.D., Chandler N.A., The progressive fracture of Lac du Bonnet granite. Int. J. Rock Mech. Min. Sci. Geomech. Abstr., 1994, 31(6), 643-659

[15] Diederichs M.S., 2007. The 2003 Canadian Geotechnical Colloquium: mechanistic interpretation and practical application of damage and spalling prediction criteria for deep tunneling. Can . Geotech. J., 2007, 44, 1082-1116

[16] Nicksiar M., Martin C.D., Evaluation of Methods for Determining Crack Initiation in Compression Tests on Low-Porosity Rocks. Rock Mech. Rock Eng., 2012, 45, 607-617

[17] Molnár, L., Vásárhelyi, B., Tóth, T., Integrated petrographic rock mechanic borecore study from the metamorphic basement of the Pannonian Basin, Hungary. Open Geosciences, 2015, 7(1), 53-64
[18] Hallbauer, D.K., Wagner, H., Cook, N.G.W., Some observations concerning the microscopic and mechanical behavior of quartzite specimens in stiff, triaxial compression tests. Int. J. Rock Mech. Sci. Geomech. Ahstr., 1973, 10, 713-726

[19] Kataoka M., Sato A., Asaue H., Obara Y., Analysis of Fracture Process of rock Based on X-ray CT Images. The 2012 World Congress on Advances in Civil, Environmental, and Materials Research (ACEM' 12) Seoul, Korea, 2012, 26-30

[20] Zang, A., Wanger, F.C., Dresen, G., Acoustic emission, microstructure, and damage model of dry and wet sandstone stressed to failure. J. Geophys. Res., 1996, 101, 17507-17521

[21] Lockner D.A., Byerlee J.D., Kuksenko V., Ponomarev A., Sidorin A., Quasi-static fault growth and shear fracture energy in granite Nature, 1991, 350, 39-42

[22] Moore, D.E. \& Lockner, D.A., The role of microcracking in shearfracture propagation in granite. J. Struct. Geol., 1995, 17, 5-114

[23] Shao J.F., Khazraei R., A continuum damage mechanics approach for time independent and dependent behaviour of brittle rock. Mechanics Research Communication. 1996, 23, No. 3, 257-265.

[24] Liu D., Manchao H.M., Cai M., A damage model for modelling the complete stress-strain relations of brittle rocks under uniaxial compression. International Journal of Damage Mechanics, 2017, First Published July 14. DOI: 10.1177/1056789517720804

[25] De Borst R., Pamin J., Geers M.G.D., On coupled gradientdependent plasticity and damage theories with a view to localization analysis. Eur. J. Mech. A/Solids., 1999, 18, 939-962

[26] Grassl P., Jirasek M., Damage-plastic model for concrete failure. Int. J. Solids Struct., 2006, 43, 7166-7196

[27] Ju Y., Xie H., Applicability of damage definition based on hypothesis of strain equivalence. Journal of Coal Science \& Engineering, 2000, 6, No. 2, 9-14

[28] Lemaitre J., A Course of Damage Mechanics. Springer, 1992

[29] Krajcinovic D., Damage Mechanics. Elsevier, 1996

[30] Arzua J., Alejano L.R., Dilation in granite during servo-controlled triaxial strength tests. Int. J. Rock Mech. Min. Sci., 2013, 61, 4356

[31] tukaszewski P., Deformational properties of flysch sandstones under conventional triaxial compression conditions. Arch. Min. Sci., 2007, 52 (3), 371-385 